www.periodicos.unimontes.br/index.php/caminhosdahistoria

\title{
A GEOGRAFIA SOCIAL DA MORTE ÀS MARGENS DA MODERNIZAÇÃO: AS TRANSFORMAÇÕES CONSERVADORAS NAS PRÁTICAS DE SEPULTAMENTO EM SÃO JOÃO DEL-REI
}

\author{
Leonara Lacerda Delfino ${ }^{1}$ \\ Márcio Eurélio Rios de Carvalho
}

Resumo: $\mathrm{O}$ artigo disserta sobre o processo de secularização da morte e o surgimento dos cemitérios públicos em São João del-Rei. Através da geografia social da morte, ou seja, do mapeamento dos locais de sepultamento, entre os anos de 1783-1850, procuramos compreender como a política sanitarista interferiu nas práticas de sepultamento e na liturgia da morte em geral. Ao longo da investigação, constatamos um processo de modernização conservadora, na medida em que os cemitérios foram construídos dentro do espaço urbano, acoplados às igrejas das irmandades, em contradição à política sanitarista que aconselhava a construção de cemitérios extramuros distantes da povoação. Para esta análise, utilizamos do método quantitativo, mediante a consulta dos registros de óbito alocados na Matriz de Nossa Senhora do Pilar de São João, além da análise qualitativa das atas da Câmara Municipal e da documentação das irmandades.

Palavras-chave: História da morte; cemitérios públicos; política sanitarista; registros de óbito; São João Del-Rei.

Abstract: The article talks about the process of secularization of death and the emergence of public cemeteries in São João del-Rei. Through the social geography of death, that is, the mapping of burial sites, between the years 1783-1850, we sought to understand how sanitary policy interfered with burial practices and the liturgy of death in general. Throughout the investigation, we noticed a process of conservative modernization, as the cemeteries were built within the urban space, coupled with the churches of the brotherhoods, in contradiction to the sanitary policy that advised the construction of extramural cemeteries far from the village. For this analysis, we used the quantitative method, by consulting the death records allocated at the Nossa Senhora do Pilar de São João Headquarters, in addition to the qualitative analysis of the minutes of the City Council and the documentation of the brotherhoods.

Keywords: History of death; public cemeteries; health policy; death records; São João DelRei.

\footnotetext{
${ }^{1}$ Sobre os autores: Leonara Lacerda Delfino é Doutora em História pela UFJF. Pós-doutoranda em História pelo PPGH/UNIMONTES. E-mail: leonaralacerda@yahoo.com.br. ORCID: https://orcid.org/0000-0001-5422-4980.

${ }^{2}$ Márcio Eurélio Rios de Carvalho é Doutor em História pela UFMG. Professor da Universidade do Estado de Minas Gerais (UEMG/Campanha). E-mail: eureliomarcio@gmail.com. ORCID: https://orcid.org/0000-00031630-6023.
} 


\section{Da sepultura sagrada à higienização da morte: a persistência dos mortos na cidade dos vivos}

A institucionalização progressiva dos sepultamentos ad sanctos remonta do século $\mathrm{V}$, quando os antigos cristãos expressaram o desejo de ser enterrados próximos às tumbas dos mártires. Estas foram consideradas relíquias sagradas e fontes de peregrinação e provedora de milagres dos fiéis católicos. Com o tempo, desenvolveu-se a crença de que a proximidade com os restos mortais dos santos ajudaria a manter a integridade da sepultura e a proteção espiritual durante o "misterioso sono," até o despertar do dia do Juízo Final, concorrendo assim para o alcance da salvação eterna (ARIÈS, 2012, p. 46). Através dos enterramentos ad sanctus os mortos passaram a se misturar com os vivos. Ao serem inumados nos solos das igrejas e em seus adros, os mortos passaram a ser lembrados permanentemente pelos seres terrenos que transitavam sobre suas covas. Esses fiéis, por sua vez, rememoravam a vivência com entes queridos, por meio das homenagens e ofícios das almas. Em comunhão com seus antepassados, os cristãos ouviam as missas fúnebres e as celebrações sagradas dedicadas aos filhos "vivos e defuntos" da Igreja de Cristo.

Deste modo, ser sepultado em solo sagrado se tornou um dos expedientes centrais da doutrina do bem-morrer católico, uma espécie de "passaporte" para a transição adequada para o outro mundo. Isto é, um ritual de passagem e de integração essencial para o processo de redenção da alma, por ser capaz de abreviar as penas de sofrimento do morto no além intermediário (o Purgatório). Segundo as orientações de Monteiro da Vide, o costume tido como "antigo e louvável" era considerado "muito proveitoso", pois quando os vivos frequentavam as igrejas, se lembravam de "encomendar a Deus Nosso Senhor, as almas dos ditos defuntos, especialmente dos seus, para que mais cedo [fossem] livres das penas do inferno provisório" (VIDE, 1853, p, 295).

Sendo assim, em São João Del-Rei, como em muitas vilas coloniais, enterrar os mortos em solo sagrado significava recriar uma prática secular, garantindo, deste modo, uma passagem segura para a vida post-mortem. Quanto mais próximo dos ícones sagrados (altar, imagens de santo, pia batismal, mais segura estava a alma de garantir a sua salvação, conforme o imaginário escatológico do bem morrer. O cortejo solene, o sacramento de extrema-unção, junto às confissões da feitura do testamento, somado aos cuidados do corpo já falecido, como a sua lavagem e o corte de unhas e cabelos, ao lado da vestimenta da mortalha e local da sepultura, compunham os chamados ritos de passagem para que alma cristã não se perdesse no meio do caminho até seu destino final (DELFINO, 2015, p. 408). 
Neste artigo, procuramos trabalhar como a ideologia liberal da política de higienista transformou os ritos fúnebres na cidade de São João Del Rei em meados do século XIX, quando os cemitérios extramuros passaram a ser regulamentados pelas leis do Império, através das comissões médicas urbanas e pelas portarias das câmaras municipais que passaram a modificar suas posturas com intuito de "civilizar" hábitos e costumes atrelados ao imaginário colonial do barroco. Neste contexto, a Igreja reformava suas práticas a partir das diretrizes do movimento de romanização, isto é, de "racionalização" das práticas populares e da autonomia da religiosidade leiga. Não obstante, as irmandades, associações leigas do período colonial, demonstraram sua força na condução do projeto de secularização da morte e participaram, junto à Câmara, das decisões das políticas sanitaristas, colocando seus termos de mudanças fúnebres, mantendo junto dos vivos, a geografia funerária dos corpos dos defuntos. Nesse sentido, na medida em que o discurso médico ganhava força e autoridade nas décadas de 1830 a 1850, em razão da proliferação de epidemias que assolaram as províncias de Rio de Janeiro, Pernambuco e Bahia, a vivência da morte barroca, conduzida, sobretudo, pelas associações leigas, manteve-se pelas práticas dos devotos que insistiram na cortejo solene, na armação das casas, no velório domiciliar e no rito da encomendação dos corpos. Quem visita o centro histórico de São João Del-Rei hoje, tem a oportunidade de testemunhar cemitérios oitocentistas, como os de São Gonçalo Garcia, São Francisco, Nossa Senhora do Carmo e Nossa Senhora do Rosário, ainda em funcionamento, construídos nesta época de perseguição às sepulturas ad sanctus.

Com a Lei Imperial de 28 de outubro de 1828, o governo monárquico delegava às câmaras municipais o dever de instaurar o "processo civilizatório" nas vilas a fim de higienizar o espaço e garantir a limpeza, segurança, fiscalização dos pesos e medidas para o funcionamento do comércio, bem como, a vigilância e supressão de lugares tidos como "insalubres", isto é, matadouros, águas paradas e tudo que pudesse emitir os chamados "miasmas pútridos e infectos". Deste modo, acreditava-se, pela campanha higienista instaurada pela Sociedade de Medicina do Rio de Janeiro, que os ares pútridos e a emanação dos miasmas, vindo dos corpos em decomposição, fossem a causa de muitas epidemias que assolaram as populações urbanas do século XIX. Nesse sentido, devemos lembrar o aspecto policialesco das autoridades sanitaristas para com a população pobre, vinculada à imundície, barbárie e, por isso, alvo da repressão violenta por parte das autoridades (CHALHOUB, 1996, p. 20). Do mesmo modo, vale retomar aos episódios como a Cemiterada, ocorrida em Salvador, cuja revolta protelou, ainda, por alguns anos a secularização da morte (REIS, 1991). 
Em São João Del-Rei não tivemos uma resistência no sentido clássico, como a Cemiterada, mas, por outro lado, um processo de negociação entre as autoridades médicas e municipais, com as autoridades eclesiásticas, juntamente com as lideranças das irmandades leigas para redimensionar os ritos de sepultamento dos mortos a fim de garantir a saúde pública dos vivos. Outrossim, o discurso sobre a insalubridade dos corpos falecidos não foi suficiente para afastar os mortos do cotidiano e da familiaridade das pessoas devotas. Dito isso, vamos expor em itens a seguir, os laços de sociabilidade comunitária no momento da morte, a prática de sepultar os mortos em solo sagrado e a segregação dos corpos nas catacumbas das igrejas. Posteriormente daremos prosseguimento à geografia social dos sepultamentos com o surgimento dos dez cemitérios identificados pelos assentos de óbitos: Cemitério da Matriz, Mercês, Rosário, São Gonçalo Garcia, São Francisco, do Carmo, das Almas, da Boa Morte, da Misericórdia e Cemitério Geral (DELFINO, 2015, p. 444).

\section{A geografia social da morte: a segregação sacra dos corpos}

A divisão da geografia funerária dizia respeito ao local da sepultura nas igrejas (espaço interno ou adro), às estratificações dos templos pertencentes às irmandades e posteriormente, aos cemitérios vinculados às associações religiosas ou ao luxo dos jazigos familiares das necrópoles civis, após o declínio definitivo das sepulturas eclesiásticas (CYMBALISTA, 2012, p. 71). Deste modo, quando consideramos as práticas fúnebres anteriores às leis sanitárias, raramente os escravos e forros foram sepultados nas igrejas das ordens terceiras do Carmo e de São Francisco. Em São João del-Rei, por exemplo, esses casos ocorreram, salvo melhor juízo, apenas com as crioulas escravas, Margarida e Gerália, quando seus corpos foram enterrados dentro da igreja de N. S. do Carmo. ${ }^{3}$

Até mesmo depois da construção dos cemitérios dessas ordens terceiras, os sepultamentos continuavam a ser restritos aos membros associados e - com raras exceções - abriram jazigo a alguns pardos. Em cemitério aberto pelos terceiros franciscanos, após a discussão da mesa em onze de outubro de $1829,{ }^{4}$ apenas João Inocente Pardo — filho de João

\footnotetext{
${ }^{3}$ Em 04/08/1831 faleceu Margarida Crioula solteira, escrava de Perpétua escolástica, sepultada na Igreja do Carmo. Dois anos depois (09/03/1833), faleceu de tísica Gerália Crioula de 24 anos, escrava de Dona Mariana Francisca de Paula, também sepultada no Carmo. Cf.: AMNSP-SJDR, Livro de Óbitos (1829, fev-1840, mar.). ${ }^{4}$ Segundo Sebastião de Oliveira Cintra (1967, p. 130), o primeiro requerimento para construção de um cemitério vinculada à Ordem terceira de são Francisco de São João del-Rei foi encaminhada em 1820. Consoante Cintra 'O assunto somente voltou a ser discutido a 11/10/1829, quando foi "proposta a necessidade de proceder-se a fatura do cemitério desta Venerável Congregação, em cumprimento da lei de primeiro de outubro de 1828 ...'.
} 
Evangelista da Cunha - morto por lombrigas, foi ali enterrado. ${ }^{5}$ Já no cemitério do Carmo, erguido por volta de $1835,{ }^{6}$ identificamos nove pardos sepultados entre 1837 a 1848 , um número bastante restrito, em demonstração à seletividade dos mortos ali enterrados. ${ }^{7}$

Analisando em pormenor a distribuição social das sepulturas na Freguesia do Pilar, podemos visualizar pela tabela 01 (ANEXO) os locais sagrados mais acessíveis aos cadáveres de escravos, libertos e livres de cor. ${ }^{8}$ Quanto aos sepultamentos em cemitérios, só podem ser considerados de forma efetiva a partir da década de 1830, com a criação dos cemitérios das irmandades da Vila, embora o Cemitério da Matriz tenha iniciado timidamente suas atividades em 1809. ${ }^{9}$ No entanto, as pessoas escravas, libertas ou pardas livres continuaram a enterrar os seus mortos em igrejas até pelo menos em 1837. Neste ano identificamos a inumação de Josefa parda inocente, filha legítima de Manoel dos Passos Nunes, sepultada dentro da Igreja de São Gonçalo Garcia, o último sepultamento realizado em igreja envolvendo esses grupos sociais. ${ }^{10}$

De acordo com nosso levantamento, certificamos que entre 1782-1850, as igrejas concentraram $76,72 \%$ dos falecidos, até mesmo porque as práticas de inumação em cemitérios foram implementadas paulatinamente após as mudanças na legislação do Império, através da imposição das leis de higiene surgidas nas primeiras décadas do Oitocentos. Reportando-se ao enfoque das sepulturas eclesiásticas, podemos notar pela exposição da tabela 01 que os locais sagrados mais acessíveis ao sepultamento dos grupos sociais mencionados foram: o Adro da Matriz, "por nada pagar" (48,39\%); a Igreja de Nossa Senhora do Rosário (14,74\%) e a Igreja das Mercês (6,26\%). Notamos também uma participação relativa de inumações desses segmentos dentro da igreja matriz $(5,33 \%)$, no entanto boa parte desses sepultamentos na matriz não mencionou a condição social dos falecidos, o que sugere o interesse gerado pelos

\footnotetext{
${ }^{5}$ AMNSP-SJDR, Assento de Óbito de João Inocente (12/12/1847). Cf.: Livro de Óbitos (1844, ago-1848, jan.)

${ }^{6}$ Consoante Cintra (1967, p. 40): "Em reunião do Consistório da Ordem do Carmo, autoriza-se ao irmão tesoureiro a pagar ao mestre de obras, Jesuíno José Ferreira, 'oitocentos réis' diários, a fim de que termine a construção do portão de ferro do cemitério."

${ }^{7}$ Foram enterrados no Cemitério do Carmo os pardos: Josefa Senhorinha de Jesus Parda (07/12/1839), Romana Maria da Silva Parda (21/03/1840), João Batista da Silva pardo (20/01/1838), Tomázia de Jesus (03/10/1845), José de Matos Pardo (20/01/1837), Gertrudes Maria da Cerqueira Parda (10/12/1847), Cândida Damiana de Oliveira Parda (18/03/1846), Francisco de Assis Lima Pardo (Reverendo, 16/02/1846) e Juliana Maria Pereira Parda (07/01/1847). Cf.: AMNSP, Livros de Óbitos (1782-1850).

${ }^{8}$ Importante lembrar que nossa amostragem não inclui as pessoas brancas, mas aqueles registros de óbitos que apresentam a condição social escrava, forra ou filho (a) de forro (a); a cor não branca do indivíduo (preta ou parda) e os grupos étnicos africanos (angola, mina, monjolo, benguela, etc.) e nativos (crioulos, cabras e mestiços). Nesse sentido, nossos dados não correspondem ao total de sepultamentos feitos nesses espaços de templos e cemitérios, mas à distribuição relacionada aos grupos sociais atrelados ao cativeiro ou próximos a ele. ${ }^{9}$ Em 06/04/1809 faleceu no "Hospital da Vila" por "bexigas", a forra Maria da Silva Crioula. Recebeu todos os sacramentos e foi sepultada no Cemitério da Matriz. Cf.: AMNSP-SJDR, Livro de Óbitos (1808, out.- 1811, jun.).

${ }^{10}$ AMNP-SJDR, Assento de Óbito de Josefa Parda (30/05/1837), Livro de Óbitos (1829, fev-1840, mar.).
} 
grupos de cor à devoção da Boa Morte, algo que será desenvolvido mais a frente. Em seguida, destacamos os enterramentos realizados na capela de devoção dos pardos de São Gonçalo Garcia $(1.91 \%){ }^{11}$

Os "anjinhos" ou "inocentes" inseridos nesta contagem (tabela 02) nem sempre recebiam campas internas separadas, como postulavam as orientações pastorais de meados do século XVIII (CAMPOS, 2013, p. 142). Essas crianças, arroladas no total de 2.576 corpos, foram em sua maioria $(70,30 \%)$ sepultadas em solo sagrado, embora $69,29 \%$ dessas covas bentas (1811) situavam-se do lado de fora da igreja paroquial. ${ }^{12}$ Quanto aos jazigos internos, nota-se que os pequenos não receberam o mesmo investimento de sepultamento em relação aos adultos. Talvez em razão dos altos índices de mortalidade infantil, seus progenitores preferissem sepultá-los em covas menos onerosas. Vale lembrar que eram considerados "anjinhos" apenas as crianças batizadas, os rebentos pagãos não mereciam, segundo o imaginário católico, alcançar o paraíso celeste por não terem purgado as manchas do pecado original, por isso estavam condenados ao limbo e não poderiam receber a proteção do solo sagrado (VOVELLE, 2010, p. 46). Ver tabelas 01 e 02.

Levando em consideração a disposição das sepulturas dentro dos templos, as mais prestigiadas se localizavam próximas aos altares principais, ou seja, "das grades para dentro". Nas matrizes, essas campas estavam reservadas aos vigários perpétuos ou aqueles fiéis distintos, como os irmãos do Santíssimo Sacramento, por conseguirem licença para enterrarem seus devotos "nos degraus do altar-mor para baixo" (VIDE, 1857, p. 299). Em alguns testamentos relatava-se o local de preferência do jazigo a ser aberto dentro da igreja. $\mathrm{O}$ Capitão José da Silva Lima - preto forro da Costa da Mina - declarou o desejo de ser coberto pelo hábito do "Glorioso S. Francisco" e, depois de encomendado e velado o seu corpo, ser enterrado próximo a "pia de água benta, da parte direita da porta principal" da capela do Rosário; templo sagrado de sua devoção e irmandade, onde serviu a Virgem com "vários cargos". ${ }^{13}$ Certamente, o irmão notório do Rosário esperava que as gotículas de água benta que, porventura, respingassem em seu túmulo, aliviassem seu estado de sofrimento durante sua expiação transitória do purgatório, como se acreditava naquela época.

Na matriz do Pilar de São João havia também a campa da Boa Morte, com seis sepulturas "livres e isentas da Fábrica," sendo dois dos seus jazigos alocados "ao pé do Altar

\footnotetext{
${ }^{11}$ AMNSP-SJDR, Assentos de óbitos (1782-1850).

${ }^{12}$ AMNSP-SJDR, Assentos de óbitos (1782-1850).

${ }^{13}$ AMNSP-SJDR, Testamento de José da Silva Lima (22/08/1788), anexo ao seu assento de óbito (26/07/1790). Livro de Óbitos (1790, mar-1792, nov.).
} 
para os Oficiais de Mesa" e quatro dispostos "no corpo da Igreja."14 Pela consulta aos assentos de óbitos, raras foram as indicações de sepulturas nessas campas, todavia, supomos que do total dos 414 cadáveres — pertencentes a esses segmentos enterrados no interior da matriz - muitos devem ter conseguido acesso às covas internas em função do atrativo devocional gerado pela irmandade dos homens pardos. ${ }^{15}$ Contudo, os registros desses obituários foram omissos, em grande parte, em esclarecer detalhadamente o local das campas, quando enterrados no interior da igreja paroquial, e o possível vínculo desses defuntos com a irmandade dos "pardos legítimos". (Ver tabela 01)

Por seu turno, notamos que a maioria $(51,85 \%)$ da população adulta enterrada dentro da matriz não mencionou a condição social. Por outro lado a participação de escravos $(22,22 \%)$ e de pessoas forras $(17,59)$ demonstrou certo equilíbrio quanto ao acesso dessas covas internas, embora muitos indivíduos de cor, sem a condição esclarecida nos óbitos, deveriam ser libertos ou descendentes deste segmento. No que se refere à procedência ou a cor desses defuntos, dificilmente os africanos tiveram chances de receber covas internas no templo da paróquia, já a categoria dos "nascidos no Brasil” representaram 84,25\%, com destaque ao grupo dos pardos, ao perfazerem 62,03\%, dos corpos ali inumados, provavelmente devotos da Boa Morte. ${ }^{16}$ (Ver tabelas 01, 02 e 03)

Fora da igreja, mas em lugar ainda revestido pelo sagrado, o adro (solo mortuário mais desprestigiado) concentrou o maior número de cadáveres de escravos e africanos, como se pode visualizar pelas tabelas 03 e 04 . Do total de 3.757 corpos enterrados, 1.255 (33.40\%) correspondiam aos inocentes e, $2.502(66.59 \%)$ às pessoas adultas. ${ }^{17}$ Desses últimos registros, $77,41 \%$ perfaziam os escravos, $12,66 \%$ não tiveram a condição social declarada, 9,31 eram libertos. Ao passo que declaradamente livres, havia somente dois falecidos, provavelmente pessoas muito pobres devido à desclassificação social daquelas covas (Ver tabela 03). ${ }^{18}$

Quanto à origem dos cadáveres adultos, 65,38\% correspondia aos sepultamentos de africanos, ${ }^{19}$ algo sugestivo quanto ao peso da segregação social da morte, pois sem o amparo e a proteção de uma irmandade religiosa durante a vida, era certo que os africanos (caso

\footnotetext{
${ }^{14}$ AMNSP-SJDR, Compromisso da Irmandade de N. S. da Boa Morte dos Homens Pardos. Vila de São João delRei, 1786, Essas campas foram reivindicadas pelo Cap. 13 "Das sepulturas que terá a Irmandade”, fl. 14.

${ }^{15}$ AMNSP-SJDR, Assentos de óbitos (1782-1850).

${ }^{16}$ AMNSP-SJDR, Assentos de óbitos (1782-1850).

${ }^{17}$ AMNSP-SJDR, Assentos de óbitos (1782-1850).

${ }^{18}$ Os registros se referem a Manoel Pereira Cabra (capitão do mato), enterrado no adro em 17/03/1783 e ao Alferes João Gomes da Costa Pardo, sepultado também neste local em 13/01/1793. Cf.: AMNSP-SJDR,Livro de Óbitos (1782, ago- 1786, jun.) e Livro de Óbitos (1792, nov.- 1796, jan.).

19 Deste segmento africano, destacaram-se os angolas $(24,78 \%)$, benguelas $(10,59 \%)$ e minas $(9,19 \%)$, ou genericamente "pretos" ou "da Costa" $(5,27 \%)$. Esta configuração remete, de certa forma, às influências do tráfico atlântico (ver capítulo 4). Cf.: AMNSP-SJDR, Livros de Óbitos (1782-1850).
} 
recebessem sepultura sagrada) teriam acesso somente às covas mais desclassificadas. Para se ter uma ideia desta segmentação na distribuição das sepulturas, é patente que os crioulos tiveram maiores oportunidades de sepultamentos dentro das igrejas. No adro, este segmento constituía 19,66 \% dos corpos ali enterrados. Já os pardos (5,55\%), cabras $(2,43 \%)$ e mestiços $(0,31 \%)$ raramente receberam jazigo neste espaço tão pouco prestigiado. ${ }^{20}$ Em vista disto, a reclassificação social no espaço funerário - mais do que em qualquer outro aspecto da existência- revela as distinções sociais representadas pelos rituais mortuários. (Ver tabelas 03 e 04).

No que tange aos sepultamentos realizados em outros templos, podemos afirmar, com exceção dos enterros realizados fora da matriz, que as tumbas oferecidas pela irmandade do Rosário foram as mais procuradas na Freguesia do Pilar, em razão da grande popularidade desta devoção em agregar filiados entre os diversos segmentos de cor. A igreja dos pretos abrigou, pelo menos, 1.145 corpos durante o período estudado; apenas 132 (11,52\%) constituíram os "anjinhos", ao passo que a maioria de 1.013 cadáveres $(88,45 \%)$ perfez os adultos. ${ }^{21}$ Em termos proporcionais, a população escrava inumada — abrigada pelo manto protetor do Rosário - só não foi maior do que a enterrada no adro da matriz, dado que sugere a intenção clara dos cativos em se integrar nesta agremiação para obter proteção durante e após a morte (ver tabelas 02, 03 e 04).

Se a proteção na hora da morte foi um dos atrativos exercidos para que o escravo aderisse a um sodalício, certamente a devoção ao Rosário se tornou a principal possibilidade, na medida em que sua força de intercessão no estágio post-mortem passou a integrar sistematicamente o imaginário de crenças desses irmãos (DELFINO, 2017, p. 305). Sendo assim, mesmo quando o confrade conseguisse se filiar em outras irmandades, muitas vezes a identificação com o Rosário se tornava explícita em ocasiões em que os testadores libertos expressavam sua preferência em ser enterrados neste solo sagrado. Esta constatação demonstra que, mesmo diante de uma legião de intercessores do purgatório, o amparo da Virgem do Rosário foi buscado principalmente por escravos $(54,68 \%)$ e libertos $(26,06 \%)$, em relação aos adultos ali sepultados, quando se tratava de procurar proteção na vida póstúmulo. $^{22}$ (Ver tabela 03). Quanto ao critério de origem desses devotos escravos ou remanescentes da escravidão ali enterrados, a maioria representava a região do centro-oeste africano (38,69\%); em seguida, predominavam os "nascidos do Brasil" (24,77\%) e, em

\footnotetext{
${ }^{20}$ AMNSP-SJDR, Assentos de óbitos (1782-1850).

${ }^{21}$ AMNSP-SJDR, Assentos de óbitos (1782-1850).

${ }^{22}$ AMNSP-SJDR, Assentos de óbitos (1782-1850).
} 
terceiro lugar, se destacavam os africanos ocidentais (15,69\%). Os angolas (17,27\%), crioulos $(16,88 \%)$ e os minas $(14,31 \%)$, - tidos como grupos de destaque na condução das decisões administrativas da irmandade - ocuparam maior espaço dos jazigos no interior da igreja. Já os benguelas $(8,68 \%)$, congos $(3,84 \%)$ e rebolos $(0,78 \%)$, mesmo muito frequentes nas entradas (1782-1850), tiveram uma adesão relativamente menor, quando comparados com os grupos anteriores, hegemônicos na mesa diretiva. ${ }^{23}$ (ver tabela 04)

O próximo contingente a se destacar na distribuição das sepulturas do espaço funerário de São João del-Rei diz respeito aos falecidos enterrados na Capela das Mercês dos Crioulos. Neste templo, identificamos a maior presença dos libertos $(36,85 \%)$, chegando a superar a participação dos escravos enterrados $(25,07 \%)$, entre os 331 falecidos adultos ${ }^{24}$ (Ver tabelas 03 e 04). Esta presença efetiva de forros ali inumados corrobora a importância do simbolismo da libertação e o ideal de afastamento das insígnias do cativeiro. Isso se justifica pelo fato dos cadáveres dos indivíduos escravos representarem um pouco mais de um quarto, enquanto aqueles sem condição social declarada (35,34\%), podendo encobrir libertos ou seus descendentes que tiveram esta informação omitida pelos registros. Ao fazer jus a proteção dos crioulos, a Senhora libertadora dos grilhões abrigou em seu recinto sagrado 71,90\% crioulos, $12,08 \%$ pardos e, 3,92\% cabras. Os africanos, como se pode acompanhar pela tabela 03, dificilmente conseguiam ser enterrados naquele templo.

Por fim, o espaço sagrado a receber uma frequência mais restrita de enterros foi o de São Gonçalo Garcia dos homens pardos. Neste localizamos apenas 78 nomes adultos nos quais a maioria $(51,85 \%)$ não tinha referência da condição social; $23,07 \%$ eram escravos e $11,53 \%$, forros. Os irmãos do santo pardo franciscano (São Gonçalo Garcia), ao admitirem pessoas brancas, morenas e pardas, ${ }^{25}$ foram bastante restritivos aos africanos. Nela se enterrou apenas uma estrangeira da África, ${ }^{26}$ fazendo dos pardos $(87,17 \%)$, o grupo hegemônico dos sepultados naquele recinto divino. ${ }^{27}$ (Ver tabelas 03 e 04).

Diante do exposto podemos certificar o quanto a sepultura eclesiástica dizia sobre a identidade social e devocional do morto. Nesse sentido, ao assegurar um espaço sagrado para o cadáver, concorria-se para a salvação de sua alma, o auxiliando no livramento das penas purgativas, reduzindo, portanto, seu sofrimento no período expiatório post-mortem. A

\footnotetext{
${ }^{23}$ AMNSP-SJDR, Assentos de óbitos (1782-1850)..

${ }^{24}$ AMNSP-SJDR, Assentos de óbitos (1782-1850). Não

${ }^{25}$ AMNSP-SJDR, Estatutos dos Gloriosos santos São Francisco de Assis e Gonçalo Garcia, sob proteção de N. S. do Amparo; Freguesia de N. S. do Pilar, São João del-Rei, 1853, cf.: Cap. 19, fl. 22.

${ }^{26}$ Cf.: Refiro-me ao assentamento de Ana Preta, casada com João Romão, sepultada em 14/02/1831 na Igreja de São Gonçalo Garcia, ver: AMNSP-SJDR, Livro de Óbitos (1829, fev. - 1840, mar.).

${ }^{27}$ AMNSP-SJDR, Assentos de óbitos (1782-1850).
} 
importância da memória visual, auditiva e olfativa, ao pisar sobre as sepulturas no sub-solo das igrejas, fazia com que os fiéis vivessem cotidianamente uma comunhão afetiva com seus mortos, os mantendo presentes não apenas nas lembranças individuais, mas nos ritos sagrados, na participação dos ofícios divinos, das missas fúnebres, dos funerais das almas, do cheiro piedoso que se acreditava exalar das tumbas sagradas... (RODRIGUES, 1997, p. 66).

A geografia social da morte demonstra como os elementos de estratificação da sociedade escravista e o aspecto hierarquizante da herança do antigo Regime estiveram presentes nos ritos de morte. Aqueles indivíduos com estatuto de "pureza de sangue" eram sepultados nas igrejas das Ordens Terceiras de São Francisco ou na Matriz do Pilar (Santíssimo Sacramento). Já os pardos, sepultados no interior da Matriz, reportavam-se à devoção e filiação à Irmandade da Boa Morte. Africanos de procedência centro-africana e da Costa Ocidental (pretos minas) tiveram seus corpos sepultados no Adro da Matriz e no Rosário. Já os nascidos no Brasil, asseguraram seus jazigos no templo das Mercês; pardos livres, na Igreja de São Gonçalo Garcia.

\section{A higienização da morte e a modernização conservadora da política cemiterial em São João Del-Rei}

Com o avanço da campanha sanitária, o caráter valorativo do cheiro dos mortos passa a se transformar em odor infeccioso, insuportável e alvo de fiscalização da nova legislação de atendimento à salubridade pública. A vigilância olfativa se estendeu para a censura auditiva, no sentido de repreender os dobres de sinos, as cantorias e outras manifestações barulhentas da morte. Falava-se muito em "corrupção dos ares" causada pelas exalações cadavéricas; as palavras de ordem naquele momento da pós-independência - quando as preocupações higienistas tomaram força - consistiam em erradicar os enterros insalubres, planejar o ambiente urbano, livrar o ambiente das contaminações miasmáticas e prevenir-se das moléstias pela desinfecção dos ares (REIS, 1991, p. 274)

Nesta perspectiva, a civilização dos costumes fúnebres estava em pauta da agenda política do partido liberal durante o Primeiro Reinado (1822-1831) e governo das Regências (1831-1840). Outrossim, o interesse em “civilizar o império" incluía, além da higienização da morte, a repressão de "algazarras, ajuntamentos, vozeias de pretos" e outras manifestações populares das vias públicas. O projeto liberal visava regulamentar a arquitetura do espaço urbano, com base numa concepção de moralidade pública, em que o ambiente citadino deveria se ver livre das imundícies causadoras de moléstias e dos marginalizados da 
sociedade — considerados desalinhados aos princípios de civilização, cidadania — isto é, das tão reivindicadas moralidade e segurança públicas. Deste modo, ao executar a limpeza das ruas, deveriam se retirar delas os "loucos, embriagados, animais ferozes ou danados", vetar “obscenidades públicas”. 28

Para além do alinhamento, iluminação e reparos de ruas, asseio das vias públicas, matadouros, a política de saúde preventiva era avessa aos costumes considerados — naquele discurso médico — como expressões da ignorância, superstições, barbárie. Por isso, os enterros eclesiásticos passaram a ser vistos como insalubres e supersticiosos (RODRIGUES, 1997, p, 132). No entanto, o processo não foi linear, nem unilateral para todos os representantes religiosos; a própria protelação e consentimento dos capelães em São João delRei, permitindo que os confrades de suas irmandades continuassem a sepultar seus mortos dentro dos templos, expressam a dificuldade ou resistência em aderir aos novos padrões de higienização. De acordo com Consuelo Carvalho (2001, p. 49), em consulta ao memorialista, Luís de Melo Alvarenga (1994), a construção do Cemitério Geral da Vila contou com a participação do Vigário Geral, ao aceitar frequentar as reuniões da Câmara junto à comissão médica da localidade. Segundo Carvalho (2001, p.47), o novo cemitério possuía catacumbas das irmandades pertencentes ao Pilar, tais como as devoções do Santíssimo, São Miguel e Almas, Nosso Senhor dos Passos e Boa Morte. As outras irmandades (São Gonçalo Garcia, Mercês e Rosário) e as ordens terceiras (Nossa Senhora do Carmo e São Francisco de Assis) passaram a construir seus cemitérios eclesiásticos, durante a intensificação da política sanitarista, quando eclodiram-se as epidemias de febre amarela e cólera nas principais aglomerações urbanas do Império.

Contudo, os enterros ilegais permaneceram em vigor na Vila por alguns anos após a reforma imperial de 1828. No entanto, em São João del-Rei não houve a construção de cemitérios extramuros, mas de necrotérios intraurbanos, situados em terrenos acoplados às igrejas, o que demonstra um vínculo dos paroquianos com as formas tradicionais de sepultamento. A preocupação em se construir um cemitério afastado da povoação só volta ser discutido pela Câmara Municipal em 1855, por ocasião de alguns casos isolados de cólera morbus identificados no Hospital da Santa Casa de Misericórdia. Segundo a sessão de 20 de setembro daquele ano, podemos notar como as autoridades religiosas foram chamadas para

\footnotetext{
28 BBCA-SJDR,Livro de Registros e Leis, Decretos, Resoluções do Conselho Geral da Província (...); Ver a aplicação do Decreto de 1828 transcrito no Título $3^{\circ}$, Art. 66, Parágrafo $3^{\circ}$ “(... ) cautela contra o perigo proveniente da divagação dos loucos, embriagados, animais ferozes danados, ou daqueles que correndo podem incomodar aos habitantes (...) Parágrafo quarto: Sobre as vozerias nas ruas em horários de silêncio, injúrias, obscenidades contra a moral pública”; fl. 60
} 
dar respaldo às decisões da Comissão Médica (a ser formada), conforme demonstra o documento:

Que se oficie ao Reverendo Vigário da Vara para que, de inteligência com o Cônego do Pároco façam proibir por hora em diante, o enterramento dos corpos mortos no cemitério, próximo à Matriz, o qual se acha colocado dentro da cidade, devendo transferir para o Cemitério do Rosário, com o consentimento da Mesa da Irmandade, ou marcar terreno apropriado, indicado pela Comissão Médica. (BBCA, Ata da Câmara de São João DelRei, 20/09/1855, Livro 32, p. 37)

Com efeito, a proibição dos sepultamentos no Cemitério da Matriz colocou como opção temporária o Cemitério do Rosário, com o pedido de anuência à Irmandade, mas a questão da localização do novo cemitério só seria resolvida no ano seguinte, quando a Câmara resolveu acatar a sugestão do pároco da cidade, designando o espaço do empreendimento próximo ao Morro do Rosário (BBCA, Atas da Câmara de São João Del-Rei, 15/01/1856, Livro 32, p. 66). Pela leitura das sessões ocorridas em outubro daquele ano, fica patente o papel pró-ativo das irmandades em erguer o novo cemitério, quando o presidente da Câmara solicita ao vigário a informação "dos recursos que cada uma dispunha e as "suas deliberações para levar a efeito a obra" (BBCA, Atas da Câmara de São João Del-Rei, 21/10/1856, Livro 32, p. 69). Deste modo, a Irmandade do Santíssimo Sacramento, mais poderosa da cidade por representar à elite de devotos, deu início à obra pelo seu maior potencial de contribuição. Em ofício encaminhado à Irmandade das Almas, a associação deixa claro que a campas mortuárias serão distribuídas de acordo com a capacidade de investimento de recursos por confraria. Sendo assim, a parte tomada por devoção no novo cemitério deveria ser em "proporção da obra" ou com a "quota em que contribuir" cada uma para elevação do novo cemitério, em lugar periférico, mas ainda nos perímetros do espaço urbano (ALVARENGA, 2009, p. 66).

Em consulta aos assentos de óbitos, observamos que antes mesmo das pressões sanitaristas de 1828, a Vila de São João já abrigava os cemitérios da Matriz e da Misericórdia $^{29}$ (cemitérios eclesiásticos). A primeira necrópole, em funcionamento desde $1809,{ }^{30}$ abrigou o maior número de mortos entre os cemitérios da localidade. Nele foram enterrados 1074 cadáveres, sendo $527(49,06 \%)$ crianças. ${ }^{31}$ Entre os 547 adultos, os escravos foram hegemônicos $(56,12 \%)$, mas dividiram o espaço mortuário com forros $(11,70 \%)$, livres

\footnotetext{
${ }^{29}$ O cemitério da Misericórdia funcionou desde 1819 e foi desativado em 1897 (ALVARENGA, 2009, p. 48).

${ }^{30} \mathrm{O}$ primeiro sepultamento identificado no Cemitério da Matriz que aparece em nossa amostra foi o de Maria da Silva Crioula Forra, falecida no "Hospital da Vila", com todos os sacramentos em 06/04/1809. Cf.: AMNSPSJDR, Livro de Óbitos (1808, fev.-1811, jun), fl. 468

${ }^{31}$ AMNSP-SJDR, Assentos de óbitos (1782-1850).
} 
de cor $(6,03 \%)$ e com aqueles sem condição declarada (25,59\%). Neste contexto em que se aproximavam as leis de cerceamento do tráfico (Leis de 1831; 1850), os segmentos dos "nascidos no Brasil" correspondiam a 58,86\%, mas havia ainda uma presença africana elevada (37,29\%). (Ver tabelas 03 e 04)

Já o cemitério da Misericórdia — situado em "frente ao Hospital” e construído entre 1818-1819 para atender os internados falecidos — ficou conhecido por oferecer jazigos aos indigentes. Nesta necrópole identificamos 91 adultos e 36 inocentes; os escravos constituíram a maioria de 78,02\% dos corpos adultos ali enterrados; muitos deles $(42,85 \%)$ eram africanos, provavelmente não tiveram recursos suficientes para providenciar uma "boa morte" (Ver tabelas 02, 03 e 04). Por fim, o Cemitério Geral da Vila - edificado por pressões do poder municipal - depois do cemitério da matriz, concentrou o segundo maior contingente de mortos, com 154 adultos e 71 inocentes. Em termos relativos, esta necrópole acolheu o maior percentual de africanos, com 50,64\% dos seus cadáveres ali enterrados, sendo a maioria deles de condição social servil $(75,97 \%) .{ }^{32}$ ver tabelas 02,03 e 04.

Quanto aos cemitérios adjacentes às irmandades de cor — Rosário, Mercês, São Gonçalo Garcia, Boa Morte - podemos dizer que o pertencente ao Rosário registrou a maior presença de corpos nele enterrados. Os irmãos da Virgem protetora dos pretos se integraram parcialmente às mudanças sanitárias, ao se reunirem em consistório da irmandade em 1831, demonstrando interesse em seguir as normas higiênicas de sepultamento, sem que com isso tivessem que abrir mão da proximidade com os mortos e da assistência religiosa. Em reunião registrada em ata houve a menção da aquisição, por compra, de um lote de terras vendido pelo Alferes Antônio José de Oliveira Barreto à associação. Nesta ata em que se formalizou o acordo comercial da propriedade, ficou explícito o objetivo de utilizar o espaço — "de sete braças e meia até a esquina (...), [ao] lado da dita Matriz" - para servir de construção do Cemitério do Rosário. ${ }^{33}$ Três anos depois, segundo Gaio Sobrinho, foi inaugurada uma capela no cemitério dos pretos a fim de atender a comodidade dos capelães para a realização dos ofícios religiosos, cerimônia de finados e a encomendação dos corpos dos irmãos. Em frente ao espaço mortuário, em seu portão de entrada, foi colocada uma inscrição "Eu já fui o que tu és, tu serás o que eu sou.” (SOBRINHO, 1996, p. 19).

O primeiro assento de óbito a fazer referência ao Cemitério do Rosário foi o de foi de Rosa Preta Forra, falecida em 17 de agosto de 1831, sob a assistência dos sacramentos da

\footnotetext{
${ }^{32}$ AMNSP-SJDR, Assentos de óbitos (1782-1850).

${ }^{33}$ AINSR-SJDR, Livro 40, Administração e Termos Diversos, Termo de ajuste de terras que fez o Reverendo Custódio de Castro Moreira a Irmandade de N. S. do Rosário para o Cemitério, (20/01/1831), fl. 10.
} 
penitência e da extrema-unção e enterrada no cemitério daquela devoção. ${ }^{34}$ Este espaço mortuário também recebeu pelo menos 117 corpos entre o período de 1831-1850; do total de 90 pessoas adultas, 45,55\% eram escravas e 18,88\% forras e 2,22\% livres de cor. $^{35}$ Os africanos "de Nação/ da Costa" - em referência à mudança da nomenclatura do tráfico, não mais cuidadosa em relatar os mercados ou portos de embarque - foram os que mais receberam jazigo (41,11\%), em seguida os "nascidos no Brasil" (36,66\%), com destaque aos crioulos $(28,88 \%){ }^{36}$

Já os cemitérios das Mercês e de São Gonçalo Garcia demonstraram certa seletividade na hora de enterrar seus cadáveres em seus espaços mortuários. Evidentemente essas restrições refletem as segregações não explicitadas nos compromissos, mas praticadas pelos irmãos em suas políticas de admissão no cotidiano confraternal. A maioria $(89,65 \%)$ dos corpos ali enterrados eram de pardos e, $82,75 \%$, sem condição social declarada. ${ }^{37}$ (Ver tabelas 03 e 04).

Nas Mercês, o primeiro a ser enterrado em seu cemitério foi o inocente José Crioulo, escravo de Maria Teodora Angélica em 29 de fevereiro de $1830 .{ }^{38}$ Assim como José, mais outras 67 crianças foram neste local enterradas entre 1830-1850. Do total de 79 adultos inumados, quase $95 \%$ nasceu no Brasil, sendo 49,36\% crioulos e 40,50\% pardos. ${ }^{39}$ Esta participação quase nula de cadáveres africanos pode estar associada à seletividade informal da confraria pelos crioulos e outros segmentos sociais mais afastados do estigma da escravidão. Quanto à condição social, a maioria dos sepultados nas Mercês $(62,02 \%)$ não teve esta referência em seus assentos. (Ver tabela 03). ${ }^{40}$ Este apontamento pode ser um indício de que muitos filhos de libertos podem ter deixado de carregar a designação de "forro/liberto ou pardo livre" em razão da transformação do processo de reconhecimento formal dos nascidos livres no Brasil (MATTOS, 2000, p. 20).

\section{Considerações Finais:}

Em vista do que foi discutido acerca das reformas cemiteriais em São João del-Rei, observamos como as irmandades buscaram se inserir no projeto de saúde pública, sem causar

\footnotetext{
${ }^{34}$ AMNSP-SJDR, Assento de Óbito de Rosa Preta Forra (17/08/1831), Livro de Óbitos (1829, fev-1840, mar.).

${ }^{35}$ AMNSP-SJDR, Livros de Óbitos (1830-1850).

${ }^{36}$ AMNSP-SJDR, Assentos de óbitos (1830-1850).

${ }^{37}$ AMNSP-SJDR, Assentos de óbitos (1830-1850).

${ }^{38}$ AMNSP-SJDR, Livro de Óbitos (1829,fev-1840, mar.) Assento de Óbito de José Inocente (19/02/1830).

${ }^{39}$ AMNSP-SJDR, Assentos de óbitos (1830-1850).

${ }^{40}$ AMNSP-SJDR, Assentos de óbitos (1830-1850).
} 
danos drásticos aos costumes funerários. Com isso, as confrarias de leigos optaram por uma modernização conservadora, evitando assim, a construção de cemitérios fora do perímetro urbano. O cemitério Geral da Vila, primeiro espaço mortuário público-civil proposto pela Câmara Municipal, deveria ter participação da autoridade eclesiástica, que contaria com uma capela ou altar "para a celebração do santo ofício da missa".O novo espaço para inumar os defuntos obedecia, em partes, às normas higiênicas de inumação, pois seu terreno permanecia próximo à cidade dos vivos.

Notamos, com o avanço da campanha sanitarista, que a morte asséptica, inodora $e$ silenciosa parece ter triunfado, com algumas ressalvas, pois a secularização da morte se fez acompanhada da participação efetiva das autoridades eclesiásticas, junto às irmandades. Não foi, portanto, uma deliberação isolada das autoridades médicas e a ingerência do poder público. Não obstante, a tentativa de expulsar os mortos da cidade dos vivos não rompeu definitivamente as lentas estruturas mentais do imaginário católico acerca do Purgatório e da crença no poder de intercessão da Virgem Maria na salvação dos mortos.

\section{Fontes Primárias:}

Arquivo da Igreja de Nossa Senhora do Rosário de São João del-Rei - (AINSR-SJDR) Livro 40, Administração e Termos Diversos, Termo de ajuste de terras que fez o Reverendo Custódio de Castro Moreira a Irmandade de N. S. do Rosário para o Cemitério, (20/01/1831).

Arquivo da Matriz de Nossa Senhora do Pilar de São João del-Rei (AMNSP- SJDR): Compromisso da Irmandade de N. S. da Boa Morte dos Homens Pardos. Vila de São João del-Rei, 1786.

Livros de Óbitos (1736-1850)

\section{Biblioteca Batista Caetano de Almeida. São João del Rei - BBCA}

Livro de Registros e Leis, Decretos, Resoluções do Conselho Geral da Província (...); Execução da Lei de 01 de outubro de 1828.

\section{Referências Bibliográficas:}

ALVARENGA, Luís de Mello. História da Santa Casa de Misericórdia de São João Del-Rei. Belo Horizonte: Gráfica Formato, 2009.

ARIÈS, Philipe. História da Morte no Ocidente. Da Idade Média aos nossos dias. Rio de Janeiro: Nova Fronteira, 2012.

CAMPOS, Adalgisa. As irmandades de São Miguel e as Almas do Purgatório: Culto e iconografia no Setecentos Mineiro. Belo Horizonte: Editora C/Arte, 2013 
CARVALHO, Consuelo de Azevedo. No silêncio dos túmulos: transformações nos ritos fúnebres na vila de São João del-Rei (1829-1858). São João Del-Rei: FUNREI, 2001.

CINTRA, Sebastião de Oliveira. Efemérides de São João del-Rei. Vol. 2. São João del-Rei: IHG/MG e Academia Municipalista de Letras de Minas Gerais, 1967.

DELFINO, Leonara Lacerda. O Rosário dos Irmãos Escravos e Libertos: fronteiras, identidades e representações do viver e morrer na diáspora atlântica. Freguesia do Pilar de São João del-Rei (1782-1850) (Tese de Doutorado, Universidade Federal de Juiz de Fora, 2015).

O Rosário das Almas Ancestrais: fronteiras, identidades e representações do viver e morrer na diáspora atlântica. Freguesia do Pilar de São João del-Rei (1782-1850). Belo Horizonte: Clio Gestão Cultural, 2017.

CHALHOUB, Sidney. Cidade Febril: cortiços e epidemias na Corte Imperial/ São Paulo: Companhia das Letras, 1996.

MATTOS, Hebe. Escravidão e Cidadania no Brasil Monárquico. Rio de Janeiro: Jorge Zahar Editora, 2000.

REIS, J. J. A Morte é uma Festa: ritos fúnebres e revolta popular no Brasil do século XIX. São Paulo: Companhia das Letras, 1991.

SOBRINHO, Antonio Gaio. Sanjoanidades: um passeio histórico e turístico por São João delRei. São João del-Rei: A voz do Lenheiro, 1996

VIDE, D. Sebastião Monteiro da. Constituições Primeiras do Arcebispado da Bahia feitas e ordenados pelo Ilustríssimo e reverendíssimo senhor D. Sebastião Monteiro da Vide $5^{\circ}$ Arcebispo e do Conselho de Sua Majestade.Proposta e aceitaem Sínodo Diocesano, que o dito senhor celebrou em 12 de junho de 1707. $1^{a}$ Ed. Lisboa 1719 e Coimbra 1720. São Paulo: Typografia 2 de dezembro de Antônio Louzada Antunes, 1853.

VOVELlE, M. As Almas do Purgatório ou Trabalho de Luto. Tradução Aline Meyer e Roberto Cattani. São Paulo: Editora UNESP, 2010.

\section{Anexo:}

TABELA 01: Locais de sepultamento segundo os assentos de óbitos (1782-1850):

\begin{tabular}{|l|l|l|}
\hline \multicolumn{1}{|c|}{ LOCAIS DAS SEPULTURAS } & $\mathbf{N}^{\mathbf{0}}$ & \% \\
\hline \multicolumn{1}{|c|}{ IGRESS } & \multicolumn{1}{|c|}{$\mathbf{5 5 6}$} & $\mathbf{7 6 . 7 2}$ \\
\hline Adro da Matriz de N. S. do Pilar & 3.757 & 48.39 \\
\hline Igreja de N. S. do Rosário & 1.145 & 14.74 \\
\hline Igreja de Nossa S. das Mercês & 486 & 6.26 \\
\hline Dentro da Matriz de N. Sra. do Pilar & 414 & 5.33 \\
\hline Igreja de São Gonçalo Garcia & 149 & 1.91 \\
\hline Campa de N. S. da Boa Morte (Matriz) & 3 & 0.03 \\
\hline Igreja de Nossa Senhora do Carmo & 2 & 0.02 \\
\hline & & $\mathbf{2 2 . 6 0}$ \\
\hline Cemitérírio da Matriz & 1.074 & 13.83 \\
\hline Cemitério Geral da Vila/ Cemitério & 225 & 2.89 \\
\hline Cemitério das Mercês & 147 & 1.89 \\
\hline Cemitério da Misericórdia/ Misericórdia & 127 & 1.63 \\
\hline Cemitério do Rosário & 117 & 1.50 \\
\hline Cemitério de São Gonçalo Garcia & 38 & 0.48 \\
\hline Cemitério da Ordem Terceira do Carmo & 13 & 0.16 \\
\hline Cemitério da Boa Morte & 11 & 0.14 \\
\hline Cemitério da Ordem Terceira de São Francisco & 2 & 0.02 \\
\hline Cemitério das Almas & 1 & 0.01 \\
\hline Não Menciona* & 27 & 0.36 \\
\hline
\end{tabular}


Dossiê | A geografia social da morte às margens da modernização (DELFINO, L.; CARVALHO, M.)

\begin{tabular}{|l|l|l|}
\hline Ilegível & 22 & 0.28 \\
\hline Rasgados & 3 & 0.03 \\
\hline TOTAL & 7.763 & 100.00 \\
\hline
\end{tabular}

Fonte: AMNSP-SJDR, Assentos de óbitos (1782-1850). Foram arrolados 7763 registros, considerando os obituários escravos, libertos e livres de cor (adultos e inocentes)

Não existem registros para os anos de 1812-1817 ; 1835-1836 e 1841-1843

TABELA 02: Locais de sepultamento segundo os assentos de óbitos de inocentes (17821850):

\begin{tabular}{|c|c|c|}
\hline LOCAIS DAS SEPULTURAS & $\mathbf{N}^{\mathbf{0}}$ & $\%$ \\
\hline $\begin{array}{l}\text { IGREJAS } \\
\end{array}$ & $\mathbf{1 . 8 1 1}$ & $\mathbf{7 0 . 3 0}$ \\
\hline Adro da Matriz de N. S. do Pilar & 1.255 & 48.71 \\
\hline Dentro da Matriz de N. Sra. do Pilar & 198 & 7.68 \\
\hline Igreja de Nossa S. das Mercês & 155 & 6.01 \\
\hline Igreja de N. S. do Rosário & 132 & 5.12 \\
\hline Igreja de São Gonçalo Garcia & 71 & 2.75 \\
\hline $\begin{array}{ll}\text { CEMITÉRIOS } \\
\end{array}$ & 744 & 28.88 \\
\hline Cemitério da Matriz & 527 & 20.45 \\
\hline Cemitério Geral da Vila/ cemitério & 71 & 2.75 \\
\hline Cemitério das Mercês & 68 & 2.63 \\
\hline Cemitério da Misericórdia/ Misericórdia & 36 & 1.39 \\
\hline Cemitério do Rosário & 27 & 1.04 \\
\hline Cemitério de São Gonçalo Garcia & 9 & 0.34 \\
\hline Cemitério da Ordem Terceira do Carmo & 4 & 0.15 \\
\hline Cemitério da Boa Morte & 1 & 0.03 \\
\hline Cemitério da Ordem Terceira de São Francisco & 1 & 0.03 \\
\hline Não Menciona* & 10 & 0.38 \\
\hline Ilegível & 8 & 0.31 \\
\hline Rasgados & 3 & 0.11 \\
\hline TOTAL & 2.576 & 100.00 \\
\hline
\end{tabular}

Fonte: AMNSP- SJDR, Assentos de óbitos (1782-1850). Foram arrolados 2.576 registros de inocentes escravos, libertos e livres de cor. Não existem registros para os anos de 1812-1817; 1835-1836 e entre 1841-1843.

TABELA 03: Locais de sepultamento segundo a condição social dos falecidos adultos (1782-1850):

\begin{tabular}{|l|l|l|}
\hline \multicolumn{2}{|c|}{ LOCAIS DAS SEPULTURAS/ Cond. Social: } & N \\
\hline \multicolumn{2}{|c|}{ IGREJAS } & $\%$ \\
\hline Adro da Matriz de N. S. do Pilar & $\mathbf{2 . 5 0 2}$ & 100.0 \\
Agregados & 2 & 0.07 \\
Coartados & 7 & 0.27 \\
Escravos & 1.937 & 77,41 \\
Filhos de forros & 4 & 1.98 \\
Forros & 233 & 9.31 \\
Livres & 2 & 0.07 \\
Não Menciona & 317 & 12.66 \\
\hline Igreja de N. S. do Rosário & $\mathbf{1 . 0 1 3}$ & 100.0 \\
Agregados & 1 & 0.09 \\
Coartados & 11 & 1.08 \\
Escravos & 554 & 54.68 \\
Filhos de forros & 12 & 1.18 \\
Forros & 264 & 26.06 \\
Livres & 3 & 0.29 \\
\hline
\end{tabular}




\begin{tabular}{|c|c|c|}
\hline Não Menciona & 168 & 16.58 \\
\hline Igreja de Nossa S. das Mercês & 331 & 100.0 \\
\hline Escravos & 83 & 25.07 \\
\hline Filhos de forros & 9 & 2.71 \\
\hline Forros & 122 & 36.85 \\
\hline Não Menciona & 117 & 35.34 \\
\hline Dentro da Matriz de N. S. do Pilar & 216 & 100.0 \\
\hline Escravos & 48 & 22.22 \\
\hline Filhos de forros & 5 & 2.31 \\
\hline Forros & 38 & 17.59 \\
\hline Livres & 13 & 6.01 \\
\hline Não Menciona & 112 & 51.85 \\
\hline Igreja de São Gonçalo Garcia & 78 & 100.0 \\
\hline Coartados & 1 & 1.28 \\
\hline Escravos & 18 & 23.07 \\
\hline Forros & 9 & 11.53 \\
\hline Livres & 4 & 5.12 \\
\hline Não Menciona & 46 & 58.97 \\
\hline Campa de N. S. da Boa Morte (Matriz) & 3 & 100.0 \\
\hline Escravos & 1 & 33.33 \\
\hline Forros & 1 & 33.33 \\
\hline Livres & 1 & 33.33 \\
\hline Igreja de Nossa Senhora do Carmo & 2 & 100.0 \\
\hline Escravos & 2 & 100.0 \\
\hline \multicolumn{3}{|c|}{ CEMITÉRIOS } \\
\hline Cemitério da Matriz & 547 & 100.0 \\
\hline Coartados & 1 & 0.18 \\
\hline Escravos & 307 & 56.12 \\
\hline Filhos de forros & 2 & 0.36 \\
\hline Forros & 64 & 11.70 \\
\hline Livres & 33 & 6.03 \\
\hline Não Menciona & 140 & 25.59 \\
\hline Cemitério Geral da Vila/ Cemitério & 154 & 100.0 \\
\hline Escravos & 117 & 75.97 \\
\hline Forros & 16 & 10.38 \\
\hline Não Menciona & 27 & 17.53 \\
\hline Cemitério da Misericórdia/ Misericórdia & 91 & 100.0 \\
\hline Agregados & 1 & 1.09 \\
\hline Escravos & 71 & 78.02 \\
\hline Forros & 7 & 7.69 \\
\hline Livres & 8 & 8.79 \\
\hline Não Menciona & 4 & 4.39 \\
\hline Cemitério do Rosário & 90 & 100.0 \\
\hline Escravos & 41 & 45.55 \\
\hline Forros & 17 & 18.88 \\
\hline Livres & 2 & 2.22 \\
\hline Não Menciona & 30 & 33.33 \\
\hline Cemitério das Mercês & 79 & 100.0 \\
\hline Agregados & 1 & 1.26 \\
\hline Escravos & 17 & 21.51 \\
\hline Forros & 5 & 6.32 \\
\hline Livres & 7 & 8.86 \\
\hline Não Menciona & 49 & 62.02 \\
\hline Cemitério de São Gonçalo Garcia & 29 & 100.0 \\
\hline Livres & 5 & 17.24 \\
\hline Não Menciona & 24 & 82.75 \\
\hline Cemitério da Ordem Terceira do Carmo & 9 & 100.0 \\
\hline Livres & 2 & 22.22 \\
\hline Não Menciona & 7 & 77.77 \\
\hline Cemitério da Boa Morte & 10 & 100.0 \\
\hline
\end{tabular}


Dossiê | A geografia social da morte às margens da modernização (DELFINO, L.; CARVALHO, M.)

\begin{tabular}{|l|l|l|}
\hline Livres & 1 & 10.00 \\
Não Menciona & 9 & 90.00 \\
\hline Cemitério da Ordem Terceira de São Francisco & $\mathbf{1}$ & 100.0 \\
Não Menciona & 1 & \\
\hline Cemitério das Almas & $\mathbf{1}$ & 100.0 \\
Não Menciona & 1 & \\
\hline Não Menciona o local & 16 & 100.0 \\
Escravos & 8 & 50.00 \\
Forros & 4 & 25.00 \\
Não menciona a cond. & 4 & 25.00 \\
\hline Ilegível & $\mathbf{1 2}$ & 100.0 \\
Escravos & 9 & 75.00 \\
Não menciona a cond. & 3 & 25.00 \\
\hline Rasgados & 3 & \\
\hline TOTAL & 5187 & \\
\hline
\end{tabular}

Fonte: AMNSP- SJDR, Assentos de óbitos (1782-1850). Foram arrolados 5187 registros, considerando os obituários escravos, libertos e livres de cor adultos. Não existem registros para os anos de 18121817 ; $1835-1836$ e entre $1841-1843$.

TABELA 04: Sepultamentos segundo as procedências étnicas dos falecidos adultos (1782-1850):

\begin{tabular}{|c|c|c|}
\hline LOCAIS DAS SEPULTURAS/ Procedências: & $\mathbf{N}^{\mathbf{0}}$ & $\%$ \\
\hline \multicolumn{3}{|l|}{$\begin{array}{ll}\text { IGREJAS } \\
\end{array}$} \\
\hline Adro da Matriz de N. S. do Pilar & 2.502 & 100.0 \\
\hline Da Costa/ Preto (a)/ de Nação & 132 & 5.27 \\
\hline A. Ocidental & 265 & 10.59 \\
\hline Cabo Verde & 9 & 0.35 \\
\hline Cobú & 18 & 0.41 \\
\hline Courana & 7 & 0.27 \\
\hline Mina & 230 & 9.19 \\
\hline Nagô & 7 & 0.27 \\
\hline Ilha da Madeira & 1 & 0.03 \\
\hline Centro-oeste africano: & 1.229 & 49.12 \\
\hline Ambaca & 1 & 0.03 \\
\hline Angola & 620 & 24.78 \\
\hline Bamba & 1 & 0.03 \\
\hline Benguela & 265 & 10.59 \\
\hline Cabinda & 12 & 0.47 \\
\hline Cabundá & 53 & 2.11 \\
\hline Camondongo & 3 & 0.11 \\
\hline Cassanje & 12 & 0.47 \\
\hline Congo & 132 & 5.27 \\
\hline Ganguela & 34 & 1.35 \\
\hline Mofumbe & 18 & 0.71 \\
\hline Monjolo & 28 & 1.11 \\
\hline Rebolo & 40 & 1.59 \\
\hline Songo & 10 & 0.39 \\
\hline África Oriental & 2 & 0.07 \\
\hline
\end{tabular}




\begin{tabular}{|c|c|c|}
\hline Moçambique & & \\
\hline Não Identificados: & 8 & 0.31 \\
\hline Bandara & 1 & 0.03 \\
\hline Mocoxo & 1 & 0.03 \\
\hline Sabaru & 2 & 0.07 \\
\hline Tapa & 1 & 0.03 \\
\hline Timbu & 1 & 0.03 \\
\hline Xambá & 2 & 0.07 \\
\hline Nascidos no Brasil: & 725 & 28.97 \\
\hline Cabras & 61 & 2.43 \\
\hline Crioulos & 492 & 19.66 \\
\hline Mestiços & 8 & 0.31 \\
\hline Pardos & 164 & 5.55 \\
\hline Não Menciona & 141 & 5.63 \\
\hline Igreja de N. S. do Rosário & 1.013 & 100.0 \\
\hline Da Costa/ Preto (a)/ de Nação & 148 & 14.61 \\
\hline A. Ocidental & 159 & 15.69 \\
\hline Cabo Verde & 5 & 0.49 \\
\hline Cobú & 3 & 0.29 \\
\hline Mina & 145 & 14.31 \\
\hline Nagô & 6 & 0.59 \\
\hline Centro-oeste africano: & 392 & 38.69 \\
\hline Ambaca & 1 & 0.09 \\
\hline Angola & 175 & 17.27 \\
\hline Benguela & 88 & 8.68 \\
\hline Cabinda & 3 & 0.29 \\
\hline Cabundá & 8 & 0.78 \\
\hline Calunga & 1 & 0.09 \\
\hline Cassanje & 4 & 0.39 \\
\hline Congo & 39 & 3.84 \\
\hline Ganguela & 10 & 0.98 \\
\hline Mofumbe & 14 & 1.38 \\
\hline Monjolo & 13 & 1.28 \\
\hline Rebolo & 28 & 2.76 \\
\hline Songo & 8 & 0.78 \\
\hline Nascidos no Brasil: & 251 & 24.77 \\
\hline Cabras & 14 & 1.38 \\
\hline Crioulos & 171 & 16.88 \\
\hline Pardos & 66 & 6.51 \\
\hline Não Menciona & 61 & 6.02 \\
\hline Ilegível/ rasgado & 2 & 0.19 \\
\hline Igreja de Nossa S. das Mercês & 331 & 100.0 \\
\hline
\end{tabular}




\begin{tabular}{|c|c|c|}
\hline Da Costa/ Preto (a)/ de Nação & 11 & 3.32 \\
\hline A. Ocidental & 6 & 1.81 \\
\hline Courana & 1 & 0.30 \\
\hline Mina & 5 & 1.51 \\
\hline Centro-oeste africano: & 8 & 2.41 \\
\hline Angola & 5 & 1.51 \\
\hline Benguela & 2 & 0.60 \\
\hline Cabundá & 1 & 0.30 \\
\hline Nascidos no Brasil: & 291 & 87.91 \\
\hline Cabras & 13 & 3.92 \\
\hline Crioulos & 238 & 71.90 \\
\hline Pardos & 40 & 12.08 \\
\hline Não Menciona & 14 & 4.22 \\
\hline Ilegível/ rasgado & 1 & 0.30 \\
\hline Dentro da Matriz de N. S. do Pilar & 216 & 100.0 \\
\hline Da Costa/ Preto (a)/ de Nação & 8 & 3.70 \\
\hline A. Ocidental & 6 & 2.77 \\
\hline Mina & 6 & 2.77 \\
\hline Centro-oeste africano: & 9 & 4.16 \\
\hline Angola & 5 & 2.31 \\
\hline Benguela & 3 & 1.38 \\
\hline Monjolo & 1 & 0.46 \\
\hline Nascidos no Brasil: & 182 & 84.25 \\
\hline Cabras & 7 & 3.24 \\
\hline Carioca & 1 & 0.46 \\
\hline Crioulos & 38 & 17.59 \\
\hline Mestiços & 2 & 0.92 \\
\hline Pardos & 134 & 62.03 \\
\hline Não Menciona & 11 & 5.09 \\
\hline Igreja de São Gonçalo Garcia & 78 & 100.0 \\
\hline Da Costa/ Preto (a)/ de Nação & 1 & 1.28 \\
\hline Nascidos no Brasil: & 76 & 97.43 \\
\hline Cabras & 4 & 5.12 \\
\hline Crioulos & 3 & 3.84 \\
\hline Mestiços & 1 & 1.28 \\
\hline Pardos & 68 & 87.17 \\
\hline Não Menciona & 1 & 100.0 \\
\hline Campa de N. S. da Boa Morte (Matriz) & 3 & 100.0 \\
\hline Pardos & 3 & 100.0 \\
\hline
\end{tabular}




\begin{tabular}{|c|c|c|}
\hline Igreja de Nossa Senhora do Carmo & 2 & 100.0 \\
\hline Crioulos & 2 & 100.0 \\
\hline \multicolumn{3}{|c|}{ CEMITÉRIOS } \\
\hline Cemitério da Matriz & 547 & 100.0 \\
\hline Da Costa/ Preto (a)/ de Nação & 114 & 20.84 \\
\hline A. Ocidental & 8 & 7.01 \\
\hline Cabo Verde & 1 & 0.18 \\
\hline Mina & 7 & 1.27 \\
\hline Centro-oeste africano: & 81 & 14.80 \\
\hline Angola & 32 & 5.85 \\
\hline Bamba & 1 & 0.18 \\
\hline Benguela & 24 & 4.38 \\
\hline Cabinda & 2 & 0.36 \\
\hline Cabundá & 1 & 0.18 \\
\hline Congo & 10 & 1.82 \\
\hline Mofumbe & 3 & 0.54 \\
\hline Monjolo & 2 & 0.36 \\
\hline Rebolo & 5 & 0.91 \\
\hline Songo & 1 & 0.18 \\
\hline $\begin{array}{l}\text { África Oriental } \\
\text { Moçambique }\end{array}$ & 1 & 0.18 \\
\hline Nascidos no Brasil: & 322 & 58.86 \\
\hline Cabras & 8 & 1.46 \\
\hline Crioulos & 166 & 30.34 \\
\hline Mestiços & 1 & 0.18 \\
\hline Pardos & 147 & 26.87 \\
\hline Não Menciona & 21 & 3.83 \\
\hline Cemitério Geral da Vila/ Cemitério & 154 & 100.0 \\
\hline Da Costa/Preto (a)/ de Nação & 15 & 9.74 \\
\hline A. Ocidental & 4 & 2.59 \\
\hline Mina & 4 & 2.59 \\
\hline Centro-oeste africano: & 59 & 38.31 \\
\hline Angola & 16 & 10.38 \\
\hline Benguela & 11 & 7.14 \\
\hline Cabinda & 8 & 5.19 \\
\hline Cassanje & 2 & 1.29 \\
\hline Congo & 10 & 6.49 \\
\hline Ganguela & 4 & 2.59 \\
\hline Mofumbe & 1 & 0.64 \\
\hline Rebolo & 6 & 3.89 \\
\hline Songo & 1 & 0.64 \\
\hline Nascidos no Brasil: & 40 & 25.97 \\
\hline Cabras & 1 & 0.64 \\
\hline
\end{tabular}




\begin{tabular}{|c|c|c|}
\hline Crioulos & 27 & 17.53 \\
\hline Pardos & 12 & 7.79 \\
\hline Não Menciona & 36 & 23.37 \\
\hline Cemitério da Misericórdia/ Misericórdia & 91 & 100.0 \\
\hline Da Costa/Preto (a)/ de Nação & 17 & 18.68 \\
\hline A. Ocidental & 2 & 2.19 \\
\hline Mina & 2 & \\
\hline Centro-oeste africano: & 20 & 21.97 \\
\hline Angola & 9 & \\
\hline Benguela & 2 & 2.19 \\
\hline Cabinda & 1 & 1.09 \\
\hline Cabundá & 1 & 1.09 \\
\hline Cassanje & 1 & 1.09 \\
\hline Congo & 3 & 3.29 \\
\hline Mofumbe & 1 & 1.09 \\
\hline Rebolo & 1 & 1.09 \\
\hline Songo & 1 & 1.09 \\
\hline $\begin{array}{l}\text { África Oriental } \\
\text { Moçambique }\end{array}$ & 1 & 1.09 \\
\hline Nascidos no Brasil: & 32 & 35.16 \\
\hline Cabras & 2 & 2.19 \\
\hline Crioulos & 19 & 20.87 \\
\hline Pardos & 11 & 12.08 \\
\hline Não Menciona & 19 & 20.87 \\
\hline Cemitério do Rosário & 90 & 100.0 \\
\hline Da Costa/Preto (a)/ de Nação & 37 & 41.11 \\
\hline A. Ocidental & 2 & 2.22 \\
\hline Mina & 2 & 2.22 \\
\hline Centro-oeste africano: & 4 & 4.44 \\
\hline Angola & 1 & 1.11 \\
\hline Benguela & 2 & 2.22 \\
\hline Rebolo & 1 & 1.11 \\
\hline Nascidos no Brasil: & 33 & 36.66 \\
\hline Cabras & 1 & 1.11 \\
\hline Crioulos & 26 & 28.88 \\
\hline Pardos & 6 & 6.66 \\
\hline Não Menciona & 14 & 15.55 \\
\hline Cemitério das Mercês & 79 & 100.0 \\
\hline Da Costa/ Preto (a)/ de Nação & 4 & 5.06 \\
\hline
\end{tabular}




\begin{tabular}{|c|c|c|}
\hline Nascidos no Brasil: & 75 & 94.93 \\
\hline Cabras & 4 & 5.06 \\
\hline Crioulos & 39 & 49.36 \\
\hline Pardos & 32 & 40.50 \\
\hline Cemitério de São Gonçalo Garcia & 29 & 100.0 \\
\hline Nascidos no Brasil: & 29 & 100.0 \\
\hline Cabras & 1 & 3.44 \\
\hline Crioulos & 2 & 6.89 \\
\hline Pardos & 26 & 89.65 \\
\hline Cemitério da Ordem Terceira do Carmo & 9 & 100.0 \\
\hline Pardos & 9 & 100.0 \\
\hline Cemitério da Boa Morte & 10 & 100.0 \\
\hline Pardos & 10 & 100.0 \\
\hline $\begin{array}{l}\text { Cemitério da Ordem Terceira de São Francisco } \\
\text { Pardo }\end{array}$ & 1 & 100.0 \\
\hline $\begin{array}{l}\text { Cemitério das Almas } \\
\text { Pardo }\end{array}$ & $\begin{array}{l}1 \\
1\end{array}$ & 100.0 \\
\hline $\begin{array}{l}\text { Não Menciona o local } \\
\text { Angolas } \\
\text { Benguelas } \\
\text { Crioulos } \\
\text { Pardos }\end{array}$ & $\begin{array}{l}16 \\
3 \\
3 \\
3 \\
7\end{array}$ & 100.0 \\
\hline $\begin{array}{l}\text { Ilegível } \\
\text { Preto de Nação } \\
\text { Angolas } \\
\text { Ganguela } \\
\text { Cabra } \\
\text { Crioulos } \\
\text { Pardos } \\
\text { Não Menciona } \\
\text { Rasgados } \\
\end{array}$ & $\begin{array}{l}\mathbf{1 5} \\
1 \\
2 \\
2 \\
1 \\
2 \\
3 \\
1 \\
3 \\
\end{array}$ & 100.0 \\
\hline TOTAL & 5187 & \\
\hline
\end{tabular}

Fonte: AMNSP-SJDR, Assentos de óbitos (1782-1850). Foram arrolados 5187 registros, considerando os obituários escravos, libertos e livres de cor adultos. Não existem registros para os anos de 1812 $1817 ; 1835-1836$ e entre $1841-1843$. 